\title{
EFFECT OF CORE STABILITY EXERCISE ON THE IMPROVEMENT OF PHYSICAL FITNESS (ENDURANCE) IN MILITARY SOLDIERS
}

\author{
Feny Oktaviyani' ${ }^{1}$, Jenal Arifin²) \\ 1)Universitas Esa Unggul, Jakarta \\ 2)Physical Military Area III/Siliwangi, Bandung 40113, West Java
}

\begin{abstract}
Background: Core stability is a primary component of functional movement, essential in daily living and athletic activities. Core stability comprises the lumbopelvic-hip complex and is the capacity to maintain equilibrium of the vertebral column within its physiologic limits by reducing displacement from perturbations and maintaining structural integrity. Core stability necessitates instantaneous changes by the central nervous system to elicit appropriate combinations and intensities of muscle recruitment for stiffness (ie, stability) as well as mobility demands of the system. This study aimed to assessed the effect of core stability exercise on the improvement of physical fitness (endurance) in military soldiers.

Subjects and Method: This was a quasy experiment. A sample of 48 military soldiers was selected by purposive sampling and divided into two groups, (1) 24 soldiers received 12 minutes run and core stability excercise, and (2) 24 soldiers received 12 minutes run. The dependent variable was physical fitness. The independent variable was core stability exercise. Physical fitness was measured by 12 minutes run test. Mean difference of physical fitness of military soldiers after intervention between groups was analyzed by independent t-test.

Results: Mean score difference of physical fitness before and after intervention in the core stability exercise group (Mean $=4.38 ; \mathrm{SD}=1.41$ ) was higher than control group (Mean= 2.42; $\mathrm{SD}=2.04)$ and it was statistically significant $(\mathrm{p}<0.001)$.

Conclusion: Core stability exercise can be used to improve physical fitness in military soldiers.
\end{abstract}

Keywords: physical fitness, core stability exercise, 12 minutes run, military soldiers

Correspondence:

Feny Oktaviyani. Universitas Esa Unggul. South Jakarta, Indonesia. Email: fenyokta8@gmail.com. 